\title{
PERFIL DOS ALUNOS INGRESSANTES DO CURSO DE PEDAGOGIA DO CAMPUS JATAÍ/ UFG NO PERÍODO DE 2004 A 2008
}

\author{
Márcia Santos Anjo Reis ${ }^{1}$ \\ Cynthia Moraes Medeiros ${ }^{2}$
}

Resumo: Esse artigo apresenta parte do resultado de pesquisa desenvolvida pela Assessoria de Graduação do CAJ/UFG, que visa analisar as características sociais, econômicas e culturais dos ingressantes no curso de Pedagogia, durante o período de 2004-2008, com o objetivo de delinear o perfil dos alunos. A análise nesta ocasião apresentada foi realizada a partir do questionário institucional preenchido pelos 350 candidatos, no curso de Pedagogia no ato da inscrição do vestibular. O perfil encontrado foi de jovem do sexo feminino acima de 20 anos, predominantemente solteira, de classe média baixa, que optou pelo curso pela perspectiva no mercado de trabalho e espera que a universidade proporcione bolsa trabalho, para que seja capaz de concluir o seu curso com qualidade e possa ajudar na renda familiar.

Palavras-chave: Perfil de alunos; Pedagogia; características sócio-economica-cultural.

\section{PROFILE OF THE STUDENTS ENTERING IN THE COURSE OF PEDAGOGY THE CAMPUS JATAÍ / UFG INTHE PERIOD 2004 TO 2008}

\begin{abstract}
This paper presents part of the result of research developed by the Office of Undergraduate the CAJ /UFG, which aims to analyze the aspects social, economic and cultural of the students entering in the course of pedagogy, in the period 2004 to 2008 , with the objective of outlining the student profiles. The analysis was performed, on this

\footnotetext{
${ }^{1}$ Doutoranda em educação e professora do curso de Pedagogia do Câmpus Jataí da Universidade Federal de Goiás (CAJ/UFG) - marcialibra@ibest.com.br

${ }^{2}$ Bolsista PROCOM e graduanda do curso de Enfermagem Câmpus Jataí da Universidade Federal de Goiás (CAJ/UFG).
} 
occasion, from the questionnaire institutional completed by 350 candidates of the Course of Pedadogy at the registration of the entrance exam. The profile found was young females with over 20 years, predominantly no married, lower-middle class, who choose the course in the prospect the labor market and expects the university will provide scholarship work, to be able to complete your course with quality and can help the family income.

Keywords: Profile of students; Pedagogy; Character socio-economic-cultural.

\section{Introdução}

Neste artigo faz-se uma breve contextualização do conjunto histórico do sistema político, econômico, social e cultural no país na década de 1980, enfocando as mudanças que acarretaram na educação superior, para compreender a lógica da implantação do curso de Pedagogia na cidade de Jataí. Em seguida, apresenta-se a análise dos dados coletados na pesquisa ${ }^{3}$ desenvolvida pela Assessoria do Câmpus Jataí da Universidade Federal de Goiás a partir do questionário institucional preenchido pelos candidatos do vestibular para o curso de Pedagogia, durante o período de 2004-2008, com o intuito de traçar o perfil dos alunos do curso.

Os dados correspondentes encontrados são subsídios indispensáveis à produção de análises sobre a realidade universitária; ao exercício necessário para a autoavaliação institucional; à formulação de políticas concernentes aos estudantes; ao planejamento do curso, procurando traçar um melhor e mais correto dimensionamento das ações de ensino, pesquisa e extensão a serem desenvolvidas.

A pesquisa é de natureza documental, tendo como objeto de análise o Questionário Sócio-Econômico-Cultural aplicado pelo Centro de Seleção da UFG, no ato de inscrição do vestibular, referentes aos candidatos aprovados no curso de Pedagogia do CAJ, no período de 2004 a 2008. Optou-se por esse recorte de tempo, por

\footnotetext{
${ }^{3}$ Pesquisa em andamento na UFG/CAJ que consiste em um levantamento de dados para traçar o perfil dos alunos dos 20 cursos de graduação em funcionamento na instituição. Neste artigo, a atenção está direcionada ao curso de Pedagogia. A pesquisa tem caráter permanente, e visa ser atualizada anualmente, em função da entrada (via vestibular) de novos alunos. Espera-se que o resultado possa contribuir para futuros diagnósticos e possíveis intervenções para melhoria dos cursos de graduação.
} 
se tratar dos dados mais atuais disponibilizados pelo Centro de Seleção. No total foram estudados 350 questionários, compostos por 56 questões fechadas que indagam a condição social, econômica e cultural dos candidatos.

Foi realizado o mapeamento de todas as questões do questionário buscando encontrar aquelas que identificassem o perfil econômico e social dos alunos de Pedagogia. Os dados foram tabulados e analisados, e serão a seguir apresentados.

\section{Elementos históricos: criação do curso de Pedagogia}

No início dos anos 1960, o Brasil enfrentava uma crise econômica e política de proporção elevada. Esse conflito se devia ao fato do aparelho de Estado não conseguir garantir à burguesia a manutenção da estabilidade do processo político, enquanto a crise econômica se agrava em função da diminuição dos investimentos, redução da entrada de capital externo, o que acarretava o declínio da taxa de lucro, e consequentemente aumentava a inflação (GERMANO, 1993).

A crise econômica, política e as mobilizações populares repercutiram no campo da educação e da cultura. No plano educacional, deu-se a aprovação da Lei de Diretrizes e Bases da Educação Nacional (LDB) no 4.024/1961, que sancionava o direito à educação, incluindo o ensino superior, e sinalizava o interesse privativo na criação e instalação de instituições de ensino superior.

O direito à educação é assegurado: I- pela obrigação do poder público e pela liberdade de iniciativa particular de ministrarem o ensino em todos os graus, na forma de lei em vigor; II- pela obrigação do Estado fornecer recursos indispensáveis para que a família e, na falta desta, os demais membros da sociedade se desobriguem dos encargos da educação, quando provada a insuficiência de meios, de modo que sejam asseguradas iguais oportunidades a todos (BRASIL, LDB 4.024/61, art. $3^{\circ}$ ).

Apesar da LDB/61 prever a criação de instituições de ensino superior (IES) em todo o país, segundo Ristoff e Giolo (2006), esse movimento de implementação e de expansão da educação superior em Goiás, foi tardio, acontecendo mais especificamente a partir da Reforma Universitária de 1968 (Lei n 5.540/1968), quando identificam-se disposições e mecanismos expansionistas, no setor público e privado, apesar de existirem algumas iniciativas de implantação desse nível de ensino em décadas anteriores. As IES de Goiás, criadas até 1960, foram a Academia de Direito de Goyaz 
em 1930, Escola de Pharmacia em 1922, Escola de Odontologia em 1923, Universidade Católica de Goiás (UCG) em 1959 e a primeira universidade federal, a Universidade Federal de Goiás em 1960 (RISTOFF e GIOLO, 2006).

Na década de 1970, a criação de novas IES não foi significativa no Estado, contudo vale ressaltar a criação em 1973 da primeira Fundação de Ensino Superior do Estado, no município de Rio Verde - Fesurv.

Pode-se dizer que o estado de Goiás vivenciou o processo expansionista na educação superior, na década de 1980, quando foram criadas fundações municipais, instituições isoladas de educação superior e novas autarquias estaduais, ajustadas a política de "criação, pelo Governo do Estado, de faculdades por meio do regime jurídico autárquico" (RISTOFF e GIOLO, 2006, p. 26). A criação de autarquias estaduais estimulou a ação dos municípios para a instituição de fundações de ensino superior, como sinônimo de prestígio e desenvolvimento. Tal movimento expansionista foi caracterizado pela interiorização da educação no estado, nas regiões sul, sudeste, oeste e sudoeste (na qual se encontra o município de Jataí).

Ao todo, foram criadas e ou consolidadas oito fundações nos municípios goianos, sendo elas: Fundação de Ensino Superior de Rio Verde (Fesurv), Fundação Integrada Municipal de Ensino Superior (Fimes), Fundação Educacional de Anicuns (FEA, Fundação de Ensino Superior de Goiatuba (Fesg), Fundação de Ensino Superior de Itumbiara (Fesit), Fundação Educacional de Catalão (Centro de Ensino Superior de Catalão), Fundação Educacional de Jataí (FEJ) (Centro de Ensino Superior de Jataí), e a Fundação Educacional de Luziânia (RISTOFF e GIOLO, 2006, p. 27). A Fundação Educacional de Jataí foi criada em 1984 com o objetivo de administrar o ensino superior dessa cidade.

Antes da criação da FEJ, em março de 1980, o então Reitor da Universidade Federal de Goiás, professor José Cruciano de Araújo assinou a Resolução no 145 que criou o Câmpus Avançado de Jataí. A partir daí, foi firmada uma parceria com a prefeitura Municipal de Jataí garantindo a consolidação do Projeto de criação do CAJ com a divisão de gastos e de responsabilidades e foi implantado em Jataí, em caráter experimental de interiorização, o curso de licenciatura em Ciências.

Somente em 1985, a UFG e a Prefeitura Municipal de Jataí/FEJ firmaram novo convênio e assim foi instalado o primeiro curso do Campus Jataí, Licenciatura em Pedagogia. Trata-se da política de expansão e interiorização da UFG por meio da 
ampliação de vagas e curso, implementado como fator de consolidação e desenvolvimento de cidades do interior. Neste convênio PMJ/FEJ/CAJ, com relação às obrigações, a UFG era responsável pela seleção e orientação pedagógica dos professores e pelo processo seletivo dos alunos; e a FEJ pela contratação e pagamento dos professores e técnicos administrativos, manutenção do CAJ e aquisição de livros e materiais de consumo.

Esse movimento de expansão e interiorização do ensino superior em Goiás, na década de 1980, ocorreu em função de pressão política do poder local e da criação pelo poder público da figura jurídica das fundações municipais, possibilitando a parceira com o setor educacional privado e, na maioria das instituições a política de não gratuidade do ensino (DOURADO, 2001).

As fundações municipais possibilitavam a transferência da concessão de autorização dos cursos, ofereciam prédios, equipamentos e ajuda financeira, além de contribuírem com a gerência e a administração das unidades de ensino. Isso caracteriza a política de privatização do público, que acontecia em função da "insuficiente normatização e fiscalização das fundações educacionais" (DOURADO, 2001, p. 57). O município assumia encargos com o nível superior que não é de sua alçada, muitas vezes sem garantir, as condições mínimas necessárias para o funcionamento do ensino básico que é sua responsabilidade, como previsto na constituição federal de educação.

A implantação definitiva do CAJ/UFG em Jataí contribuiu de certa forma para o crescimento e desenvolvimento da cidade. A universidade tem a responsabilidade de produzir, disseminar e renovar o conhecimento, assim como, pela sua própria condição acadêmica, científica e filosófica, tem a função de preparar profissionais com um entendimento aprofundado do seu campo de intervenção e com outras áreas. Visa possibilitar aos acadêmicos um discernimento apurado para que tenham consciência de seus compromissos sociais, e sejam capazes de se anteciparem às mudanças, sabendo “prosseguir com desenvoltura sua evolução permanente" (MORAIS, 1992, p. 58).

A opção pelo curso de Pedagogia justifica-se pelo fato de contribuir com a formação dos educadores municipais da cidade e por ser um curso que não demanda inicialmente de muitos recursos financeiros para sua implementação.

A pedagogia, segundo Libanêo (1998), serve para investigar a natureza, as finalidades e os procedimentos necessários às práticas educativas com o objetivo de propor a realização desses processos nos vários contextos em que essas práticas 
ocorrem. Ela se constitui, sob esse entendimento, em um campo de conhecimento que possui objeto, problemáticas e métodos próprios de investigação, configurando-se como "ciência da educação".

Após a regulamentação da LDB no 9.394/1996, houve a implantação de nova matriz para o curso de Pedagogia em Jataí, apenas em 2004. Na nova matriz curricular implementada, o curso deixou de ser regime anual e passou a ser semestral, disponibilizando um total 70 vagas, distribuídas em duas turmas de 35 alunos, ambas no turno noturno.

Em 2009, o CAJ/UFG aderiu ao Programa de Apoio a Planos de Reestruturação e Expansão das Universidades Federais (REUNI), instituído pelo Decreto $n^{\circ} 6.096$ de 24/04/2007, proposto no segundo mandato do Governo Lula, e o curso de Pedagogia ampliou mais dez vagas. Atualmente, o curso disponibiliza 80 vagas, divididas entre o período matutino e noturno.

Os processos seletivos para o vestibular estão sempre em pauta nas discussões sobre a qualidade do ensino e os mecanismos de exclusão ao acesso ao ensino superior. Saber quem é o aluno que entra na universidade é um ponto chave para que se possa avaliar com embasamento se o vestibular oferece condições iguais a todos, além de servir como balizamento para políticas de mudanças tanto no vestibular quanto da educação básica. Com base nestas considerações, este trabalho visa estudar e analisar as características sociais, econômicas e culturais dos alunos de Pedagogia (licenciatura) que ingressam na UFG/CAJ, via vestibular, durante o período de 2004-2008, com objetivo de delinear o perfil dos alunos do curso.

\section{Análise e discussão dos dados coletados}

A pesquisa documental foi realizada tendo como objeto de análise o Questionário Sócio-Econômico-Cultural aplicado pelo Centro de Seleção da UFG no ato de inscrição do vestibular dos 350 candidatos aprovados no curso de Pedagogia do CAJ, no período de 2004 a 2008. Foi realizado o mapeamento das 56 questões que compõe o questionário procurando identificar o perfil dos alunos do referido curso. Os dados foram tabulados e analisados, e a seguir apresentados.

Do total de ingressantes, $97,66 \%$ são do sexo feminino e apenas 2,34\% são do sexo masculino. Este resultado demonstra que permanece ainda a idéia de que educar 
crianças é tarefa feminina, pois a mulher é mais calma, dócil, tranqüila e seu salário é apenas para complementar a renda familiar. Essa proporção se manteve estável durante os cinco anos analisados. Observa-se que 58,36\% dos ingressantes são solteiros, o que supostamente, indica não terem, diretamente, responsabilidades familiares; 32,24\% são casados; $5,32 \%$ são separados ou divorciados e 4,22\% tem outro tipo de relacionamento.

Quando analisada a faixa etária, 22,78\% dos ingressantes possuem entre 17 a 19 anos, $37,46 \%$ tem entre 20 a 25 anos e $38,96 \%$ ingressaram na faculdade com mais de 25 anos. Esses números se repetem entre os anos com pequenas variações. Isso nos leva a pensar que são alunos que ficaram algum tempo sem estudar, ou por necessidade de trabalhar para ajudar em casa, deixaram para prestar vestibular mais tarde, pois um número significativo desses tem acima de 25 anos.

Quanto à moradia nos últimos dois anos, 86,3\% moram em casa própria (da família), e 13,7\% em outra moradia (repúblicas e outros). Isso evidencia que a maioria dos alunos do curso de Pedagogia é da própria cidade, o que não demanda a necessidade da instituição em ampliar a ofertar de bolsa moradia, para ajudar os alunos a se manterem na cidade para estudar.

Com relação à situação financeira, 51,04\% dos alunos começaram a trabalhar entre os 14 e 18 anos e apenas $11,1 \%$ nunca trabalhou. Destes 51,04\% que trabalham, 42,5\% fazem jornada de trabalho semanal de 40 horas e o salário mensal é de até $\mathrm{R} \$ 480,00$. Percebe-se que os indivíduos começaram a trabalhar quando ainda eram menores de idade, o que de certa forma nos leva a crer que, a condição financeira das famílias é baixa. Essa constatação é comprovada com os dados das questões seguintes.

Quando indagados sobre a participação do seu salário na vida econômica da sua família, 72,4\% responderam que seu salário contribui parcialmente com as despesas familiares, como aluguel, água, luz, alimentação e 27,6\% o seu rendimento é exclusivo para gastos pessoais.

Com relação ao total de pessoas que contribuem para a obtenção da renda familiar, os dados obtidos foram: uma $(30,26 \%)$, duas $(48,56 \%)$, três $(16,26 \%)$, quatro ou mais $(4,92 \%)$. Comparando estes dados com o da participação de seu salário com a renda familiar, consta-se que a renda da maioria é constituída do salário do aluno e de mais uma pessoa. Logo, para o aluno poder fazer um curso com tranqüilidade e não 
precisar trabalhar 40 horas semanais e ter mais tempo para se dedicar aos estudos seria interessante a instituição em pensar em políticas de expansão de bolsas PIBIC, PIVIC, PROLICEN, PROCOM, para auxiliar o aluno na sua formação.

O item que "pesa" mais no orçamento da família é a alimentação com $62,54 \%$, seguido por tratamento médico e odontológico com 13,38\%, o restante está entre: instrução, lazer, viagem, moradia, transporte, vestuário. Nota-se pela idade que começou a trabalhar, salário mensal, e quantidade de pessoas que contribuem nas despesas, que o ingressante no curso deve ajudar com algum rendimento para que a família possa ter condições mínimas de qualidade de vida.

A maioria dos ingressantes $(80,52 \%)$ estudou em escola pública, $(4,82 \%)$ completou seus estudos somente na rede privada e $(14,4 \%)$ estudou, parte em escola pública e parte na privada. Esses dados revelam que o curso de Pedagogia da UFG/CAJ está preenchendo a maioria de suas vagas com alunos da rede pública, o que vem atender aos interesses das políticas públicas atuais. Mas também não devemos nos enganar, pois quando analisamos outros cursos, considerados de "ponta", como direito, medicina veterinária e outros, ofertados no $\mathrm{CAJ}$, esta porcentagem não se repete.

Dos ingressantes, $56 \%$ concluíram o ensino médio no turno noturno e $44 \%$ concluíram no turno diurno (matutino e/ou vespertino), o que de certa forma justifica a maior procura dos candidatos pelo turno noturno, pois trabalham e pretendem continuar trabalhando enquanto fazem o curso, pois o salário deles ajuda nas despesas familiares. Com relação a modalidade do ensino médio que concluíram, os dados revelam que fizeram o ensino médio regular (57,98); o compacto $(3,68 \%)$; o técnico $(7,68 \%)$ e o supletivo (13,68\%). Observa-se que a procura pelo supletivo e o compacto ainda representa uma porcentagem significativa $-17,38 \%$.

Quando indagados sobre quantas vezes prestaram vestibular, 44,9\% disseram nunca terem prestado; apenas uma vez, 25,96\%; duas vezes, 15,1\%; três vezes 9,98\%; quatro ou mais vezes, 3,66\%. Com relação a informação se fizeram cursinho pré-vestibular, $70,78 \%$ não fizeram e apenas $29,22 \%$ cursaram, o que mostra o fácil acesso ao curso, consequência de ter cursado ensino médio regular ou devido à baixa concorrência.

Dentre os motivos principais levantados de optar pelo curso de Pedagogia encontramos: perspectivas no mercado de trabalho (26,56\%); adequação às habilidades/aptidões pessoais $(25,94 \%)$; possibilidade de realização pessoal $(12,8 \%)$; 
necessidade de ampliar os conhecimentos (11,66\%); inexistência de outro curso pretendido em outra instituição pública em Goiás (8,54\%); o restante declarou ser outra a motivação principal pela escolha do curso.

Questionados sobre o que gostariam que a UFG disponibilizasse para contribuir com sua permanência no curso, responderam: bolsa trabalho $(53,14 \%)$; assistência médica e odontológica (24,24\%); programas culturais e artísticos (13,08\%); bolsa alimentação (3,98\%; atividades de esporte e lazer $(3,38 \%)$ e por último, apoio para alojamento $(1,96 \%)$. Os ingressantes pretendem se manter no curso com o próprio trabalho $(76,24 \%)$; com recursos dos pais $(10,26 \%)$; com a ajuda de outros $(7,94 \%)$ e com bolsas de estudos (5,38\%). Esses dados confirmam que a jornada de trabalho precisa ser reduzida para que eles possam dedicar mais aos estudos e que os serviços médicos e alimentação de alguma forma pesam no orçamento da família.

O meio de transporte mais utilizado segundo os ingressantes é a moto $(23,96 \%)$, seguida por carro próprio ou da família (22,52\%), transporte coletivo $(18,82 \%)$ entre outros, o que sugere um equilíbrio entre a condição financeira, por possuírem carro ou moto.

Os fins da utilização do computador são para atividades profissionais $(31,1 \%)$, trabalhos escolares $(18,9 \%)$; navegação na internet $(10,82 \%)$; entretenimento $(8,5 \%)$; outros fins, $(14 \%)$; mas $10,8 \%$ não sabiam usar computador.

Em relação à língua estrangeira extracurricular, 83\% nunca fizeram nenhum curso e $17 \%$ frequentaram. As atividades extra-escolares que participam são: religiosas, $28,24 \%$, artísticas e culturais 20,24\%; esportivas $10 \%$; entre outras, que qualifica a Pedagogia um curso de gostos heterogêneos.

\section{Considerações finais}

Nota-se que os ingressantes no curso de Pedagogia do CAJ a maioria são jovens acima de 20 anos, do sexo feminino. São predominantemente solteiras, sem filhos, moram com os pais, tem uma família grande, de mais de três irmãos, em média. Estão interessados em estudar no período noturno o que possibilita trabalharem durante o dia para se manterem na universidade.

A origem dos alunos de Pedagogia é humilde. A pesquisa deixa claro que a maioria é oriunda de escola pública, cursou o Ensino Médio regular (3 anos) no turno 
matutino, não fez cursinho, mas ficou um bom tempo sem estudar, mais ou menos 5 anos, e a opção pelo curso foi devido as perspectivas no mercado de trabalho.

Com relação ao meio de transporte utilizado houve certo equilíbrio entre moto, carro próprio (família) e ônibus (transporte coletivo). A maioria utiliza o computador para atividades profissionais ou para fazer trabalhos escolares; são alunos que não fizeram curso de língua estrangeira extracurricular; e as atividades extraescolares que costumam praticar estão ligadas a cultura, atividades artísticas.

A obtenção da renda familiar, na maioria se restringe a duas pessoas, e o gasto está basicamente direcionado para a alimentação e saúde. Eles esperam que a universidade proporcione bolsa trabalho, para que possam concluir o seu curso com qualidade e possam ajudar na renda familiar.

Dizem ter escolhido o curso de Pedagogia por gostarem da área da educação e se identificarem com ela, e também pelas oportunidades oferecidas pelo mercado de trabalho. Nas palavras de Freire (2000, p. 67): "Não é possível refazer este pais, democratizá-lo, humanizá-lo, torná-lo sério, com adolescentes brincando de matar gente, ofendendo a vida, destruindo o sonho, inviabilizando o amor. Se a educação sozinha não transforma a sociedade, sem ela tampouco a sociedade muda".

A educação é capaz de transformar a sociedade, somente com ela podemos formar cidadãos conscientes responsáveis e de caráter. É da responsabilidade dos futuros educadores transmitirem essa educação adiante para todos que vão ser o futuro do país.

Esses dados possibilitam conhecer o público alvo do curso e pensar em ações que possam contribuir com a formação profissional dos alunos, bem como elaborar projetos de extensão que atendam a nossa comunidade. Espera-se que o resultado desta pesquisa possa contribuir para futuros diagnósticos e possíveis intervenções para melhoria do curso de Pedagogia dentro da Instituição.

\section{Referências bibliográficas}

BRASIL. Lei no 4.024/61, que estabelece as Diretrizes e Bases da Educação Nacional. Disponível em: <http://www.presidencia.gov.br>. Acesso em 2 fev. 2008.

DOURADO, Luiz Fernandes. A interiorização do ensino superior e a privatização 
do público. Goiânia: UFG, 2001.

FREIRE, Paulo. Pedagogia da indagação: cartas pedagógicas e outros escritos. São Paulo: UNESP, 2000. p. 67

GERMANO, José Wellington. Estado militar e educação no Brasil (1964-1985). São Paulo: Cortez, 1993.

LIBÂNEO, J. C. Pedagogia e pedagogos, para quê? São Paulo: Cortez, 1998.

MORAIS, J. F. R. Universidade: seus desafios neste final de século. Pró-posições, v. 3, n. 2(8), p. 51-65, 1992.

RISTOFF, Dilvo.; GIOLO, Jaime. A educação Superior no Brasil - Panorama Geral. In: INSTITUTO NACIONAL DE ESTUDOS E PESQUISAS EDUCACIONAIS ANÍSIO TEIXEIRA. Educação Superior Brasileira: 1991-2004 (Goiás). Brasília: Inep, 2006. p. $13-20$. 